\title{
Comparison of Methods for Determining the Water Absorption of Glazed Porcelain Stoneware Ceramic Tiles
}

\author{
Angela Waterkemper Vieira ${ }^{a, b}$, Murilo Daniel de Mello Innocentini ${ }^{c}$, Erlon Mendes ${ }^{b}$, Thauan Gomes ${ }^{b}$ \\ Aline Demarch $^{a}$, Oscar Rubem Klegues Montedo ${ }^{b}$, Elidio Angioletto ${ }^{b}$ \\ ${ }^{a}$ Eliane Revestimentos Cerâmicos, Cocal do Sul, SC, Brazil \\ ${ }^{b}$ Universidade do Extremo Sul Catarinense - UNESC, Criciúma, SC, Brazil \\ ${ }^{c}$ Curso de Engenharia Química, Universidade de Ribeirão Preto - UNAERP, Av. Costabile Romano, \\ 2201, 14096-900, Ribeirão Preto, SP, Brazil
}

Received: January 17, 2017; Accepted: October 11, 2017

\begin{abstract}
This work evaluated the water absorption of glazed porcelain stoneware ceramic tiles using three different methods. Two methods were based on a procedure of boiling in water, specified by standards ISO 10545 and ASTM C373, and the third was the vacuum method proposed by the standard ISO 10545. The three products produced under the three different firing conditions were tested according to a $2^{2}$ factorial design, with intervening factors of the boiling time and immersion time for the methods involving boiling, and of pressure and immersion time for the vacuum method. The maximum saturation of the plates was evaluated by helium gas pycnometry testing. The results showed that no sample saturation occurs in the boiling water absorption test performed according to the conditions established by standards ISO 10545 and ASTM C373. The values of open porosity, using the method of helium gas picnometry, showed absolute values of saturation higher than those presented by the water absorption measured according to the current standards. Thus, the results showed that the current methods for determining the water absorption of glazed porcelain stoneware ceramic tiles do not guarantee the complete saturation of the plates and, therefore, they are not able to correctly measure this property.
\end{abstract}

Keywords: ceramics, glazed porcelain stoneware, water absorption, porosity, technical standards

\section{Introduction}

Ceramic materials have many applications with uses in several branches of science and technology ${ }^{1}$. Glazed porcelain stoneware ceramic tiles show values of water absorption (WA) under $0.5 \%$, because of the reduced particle size obtained during the grinding step, the high content of flux agents and the pressing at high pressures ${ }^{2}$. They are characterized by high density (2380-2450 $\left.\mathrm{kg} / \mathrm{m}^{3}\right)$ and limited porosity with small pore sizes $(<50 \mathrm{~mm})^{3}$. They show high breaking strengths with values above $2 \mathrm{kN}$ and reaching $8 \mathrm{kN}$ for pieces with thicknesses exceeding $15 \mathrm{~mm}^{4}$.

The manufacturing process of wall and floor ceramic tiles requires the control of physical properties such as porosity and WA. When traditional methods of quality control are used, such control takes a long time ${ }^{5}$, despite its great importance, as the standards for ceramic tiles, including NBR $15463^{6}$, NBR $13818^{7}$, ISO $13006^{8}$ and ASTM ${ }^{9}$, classify them according to their WA.

WA is an indirect measure of the open porosity of the ceramic body and is calculated by the ratio between the mass of remained water in the pores of the plates under saturation and the mass of the dry sintered product. The WA relates directly to the residual open porosity and is, therefore, also related to the ceramic microstructure ${ }^{10}$.
The ceramic material used in this study is the glazed porcelain stoneware, as it is the ceramic tile that presents the best technical requirements. Therefore, it holds greater added value as a high-level glazing material, with a very compact structure, low porosity, and high technical performance ${ }^{11}$. As such, it requires greater control of its technical characteristics during the manufacturing process.

\section{Experimental Procedure}

Representative quantities of production batches of three glazed porcelain stoneware ceramic tiles, identified as Product A, Product B, and Product C, were collected from the output of an industrial roller kiln. A previous WA test was performed according to the procedures specified by ISO $10545^{12}$.

We used a $2^{2}$ factorial design, considering the factors of boiling time and water immersion time, for the WA methods based on boiling, and vacuum pressure and water immersion time for the WA vacuum method (Table 1). Each factor was varied at two levels

Chemical characterization of the samples was performed with an X-ray fluorescence spectrometer by wavelength dispersion (XRF, OXFORD Instruments X-Supreme 8000, England). Crystalline phases were determined by an X-ray diffractometer (XRD, Shimadzu, XRD-6000 model, Japan). 
Table 1. Experimental design with the combinations among each factor.

\begin{tabular}{lcccc}
\hline \multicolumn{1}{c}{ Factors } & Procedure & & Levels \\
\cline { 3 - 4 } Boiling time (h) & ISO 10545 & $\mathbf{- 1}$ & $\mathbf{0}$ & $\mathbf{1}$ \\
Water immersion time (h) & & 1 & 2 & 5 \\
Boiling time (h) & ASTM C 373 & 2 & 4 & 24 \\
Water immersion time (h) & & 2 & 5 & 8 \\
Vacuum pressure (kPa) & Vacuum method proposed by ISO & 4 & 24 & 44 \\
Water immersion time (min) & & 6 & 10 & 40 \\
\hline
\end{tabular}

*Conditions determined by respective standards.

The apparent densities of the samples were determined by immersion in water (Archimede's principle, $22^{\circ} \mathrm{C}, d=0.9978$ $\mathrm{g} / \mathrm{cm}^{3}$ ), using a Tepron scale, model Mark 4100, with $0.01 \mathrm{~g}$ accuracy, where the density was determined at nine different points of the piece.

The ISO $10545^{12}$ procedure for determining water absorption as per consists of weighing the samples after they are completely dried (dry mass), and then immersing them in boiling water for $2 \mathrm{~h}$. The heating system is then switched off and the ceramic pieces remain immersed in water to cool naturally for $4 \mathrm{~h}$ (water immersion time) for saturation. After this procedure, the excess moisture on the sample surfaces is removed with a damp cloth and their mass is again measured (wet mass).

Concerning the ASTM C373 procedure $^{9}$, the dried samples are cut into a $20.5 \mathrm{~cm} \times 20.5 \mathrm{~cm}$ format, weighed, and immersed in boiling water for $5 \mathrm{~h}$. Then the heating system is switched off and the ceramic pieces remain immersed in water for another $24 \mathrm{~h}$ (water immersion time) for saturation. After this procedure, the excess moisture on the sample surfaces is removed with a damp cloth and their mass is again measured.

The vacuum procedure proposed by ISO consists of subjecting the dried samples, cut into pieces of $20 \mathrm{~cm} \times 20$ $\mathrm{cm}$ and weighed, to a vacuum condition of $10 \mathrm{kPa}$ pressure for $30 \mathrm{~min}$. After this period, the samples are immersed in water at room temperature $\left(21-23{ }^{\circ} \mathrm{C}\right)$ for $15 \mathrm{~min}$, for saturation. Excess moisture is removed from the sample surfaces with a damp cloth and their mass is measured again.

This weighing procedure used a digital scale with 0.01 g accuracy. The water absorption was calculated with the equation (1):

$$
W A=\frac{m_{2}-m_{1}}{m_{1}} \cdot 100
$$

where $W A$ is the water absorption (\%), $m_{1}$ is the dry mass (g), and $m_{2}$ is the wet mass (g).

The time required to achieve sample saturation was also determined, which relied on determining the WA behavior of the ceramic tiles over time.

A helium gas pycnometry test (Quantachrome, Ultrapyc model $1200 \mathrm{e}$, England) was used to determine the open porosity of each sample. The values obtained were used to estimate the corresponding values of WA $\left(W A_{H e}\right)$. Subsequently, these estimates were used for comparison with the WA values determined by the current standards. First, the volume of pores $\left(V_{\text {pores }}\right)$ of each tested piece was measured. An aliquot of each sample with a shape of approximately $13 \mathrm{~mm} \times 20 \mathrm{~mm}$ was collected and dried in a lab oven at $110 \pm 2{ }^{\circ} \mathrm{C}$ for $4 \mathrm{~h}$. Then, each aliquot was tested by the helium gas pycnometer, yielding the value of the actual volume $\left(V_{\text {real }}\right)$ of the tested piece (aliquot). Three measurements were made for each aliquot of each sample. Then, each aliquot was waterproofed with an oil repellent $(2 \mathrm{X})$ and immersed in water, using Archimedes' principle, on a Shimadzu scale, model AUY 220. The apparent volume of each aliquot (volume of displaced water, $V_{\text {apparent }}$, in $\mathrm{cm}^{3}$ ) was obtained by equation 2 :

$$
V_{\text {apparent }}=\frac{\text { buoyancy }}{d_{\text {water }}}
$$

where buoyancy is the mass of the piece immersed in water ( $\mathrm{g}$ ) and $d_{\text {water }}$ is the density of water at the temperature at which the test was performed $\left(22^{\circ} \mathrm{C}, d=0.9978 \mathrm{~g} / \mathrm{cm}^{3}\right)$. Five measurements were made for each aliquot of each sample.

The volume of the pores $\left(V_{\text {pores }}\right)$ was calculated using the difference between $V_{\text {apparent }}$ and $V_{\text {real }}$ as per equation 3:

$$
V_{\text {pores }}=V_{\text {apparent }}-V_{\text {real }}
$$

Therefore, the limit of water saturation, considering on all the open pores could be filled by water, was determined from the modified helium gas pycnometry test $\left(W A_{H e}\right)$ and calculated by equation 4 :

$$
W A_{H e}=\frac{V_{\text {pores }} \cdot d_{\text {water }}}{m_{\text {sample }}} .100
$$

\section{Results and Discussion}

Table 2 shows the results of the chemical analysis. The content of the elements of the materials tested and of a typical porcelain stoneware are very similar ${ }^{13}$. The greatest differences are related to the contents of $\mathrm{MgO}$ and $\mathrm{Na}_{2} \mathrm{O}$; 
Table 2. Chemical analysis (wt \%) of the investigated samples.

\begin{tabular}{|c|c|c|c|}
\hline Oxides & Product A & Product B & Product $\mathrm{C}$ \\
\hline $\mathrm{SiO}_{2}$ & 69.90 & 69.83 & 70.20 \\
\hline $\mathrm{Al}_{2} \mathrm{O}_{3}$ & 20.83 & 20.37 & 19.95 \\
\hline $\mathrm{TiO}_{2}$ & 0.46 & 0.46 & 0.47 \\
\hline $\mathrm{Fe}_{2} \mathrm{O}_{3}$ & 2.41 & 2.39 & 2.38 \\
\hline $\mathrm{CaO}$ & 2.00 & 2.14 & 2.05 \\
\hline $\mathrm{MgO}$ & 1.58 & 1.71 & 1.92 \\
\hline $\mathrm{Na}_{2} \mathrm{O}$ & 1.60 & 1.68 & 1.39 \\
\hline $\mathrm{K}_{2} \mathrm{O}$ & 2.46 & 2.51 & 2.62 \\
\hline $\mathrm{ZnO}$ & 0.00 & 0.10 & 0.06 \\
\hline $\mathrm{ZrO}_{2}$ & 0.38 & 0.42 & 0.35 \\
\hline $\mathrm{BaO}$ & 0.24 & 0.25 & 0.26 \\
\hline
\end{tabular}

however, this compositional difference cannot be related to the differences in WA behaviors presented below. One can be said the same for the crystalline phases identified in these materials.

As seen in Figure 1, quartz ( $\mathrm{SiO}_{2}$, JCPDS 46-1045), mullite ( $\left.\mathrm{Al}_{6} \mathrm{Si}_{2} \mathrm{O}_{13}, \mathrm{JCPDS} 15-0776\right)$, and $\mathrm{CaAl}_{2} \mathrm{Si}_{2} \mathrm{O}_{8} \cdot 4 \mathrm{H}_{2} \mathrm{O}$ (JCPDS 20-0452) are present in all three samples. It can also be identified glassy phase in all the investigated materials. These phases are typical of porcelain stoneware tiles ${ }^{13}$.

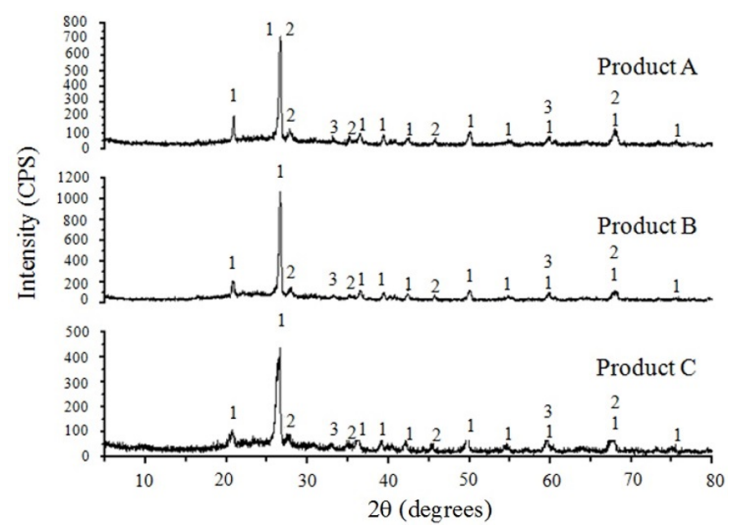

Figure 1. XRD patterns of the studied materials: 1 - Quartz $\left(\mathrm{SiO}_{2}\right)$, 2 - Mullite $\left(\mathrm{Al}_{6} \mathrm{Si}_{2} \mathrm{O}_{13}\right), 3-\mathrm{CaAl}_{2} \mathrm{Si}_{2} \mathrm{O}_{8} \cdot 4 \mathrm{H}_{2} \mathrm{O}$.
Figure 2 shows the WA as a function of the water immersion time obtained by the standard ISO 10545 for different water boiling times. In this figure, condition (b) represents the boiling time and the water immersion time established by the standard ISO 10545. Under these conditions, the three analyzed products show WA values within the specified value $(0.5 \%)$, although the WA increases from Product $A$ to Product $\mathrm{C}\left(\mathrm{WA}_{\mathrm{A}}<\mathrm{WA}_{\mathrm{B}}<\mathrm{WA}_{\mathrm{C}}\right)$. The conditions (a) and (c) represent variations in the boiling time ( 1 and $5 \mathrm{~h}$ ) and in the water immersion time ( 2 and $24 \mathrm{~h})$, related to the conditions established by the standard ISO 10545 . Figure 2 shows that the WA does not vary depending on the boiling time, but it does vary with different water immersion times. When comparing conditions (a) and (c), regardless of the water immersion time and the products examined, the WA values are statistically the same for both boiling times. However, regardless of the boiling time and the type of product, the WA value is higher for longer immersion times. Since the WA does not depend on the boiling time, it may be noted that the WA values for the $4 \mathrm{~h}$ water immersion time are between the values for the immersion times of 2 and $24 \mathrm{~h}$. Table 3 shows the statistical analysis of the values shown in Figure 2.

The P-test indicates the significance that the variable in question (boiling time or water immersion time) shows on the dependent variable (WA). Smaller P-test values indicate greater variable significance. In general, values lower than 0.005 (95\% confidence) are accepted as significant. In this case, Table 3 shows that the water immersion time presents the lowest values of the P-Test for the three evaluated products. The interaction between the independent evaluated variables shows also no significance. In this way, one can say with 95\% confidence that the water immersion time influences the WA results for the evaluated products, with very good agreement with the behavior shown in Figure 2.

The F-test indicates the effect that the independent variable (boiling time or water immersion time, in this case) shows on the dependent variable (WA). Higher F-test values correspond to greater effects on the dependent variable. In this case, Table 3 shows that, although the boiling time

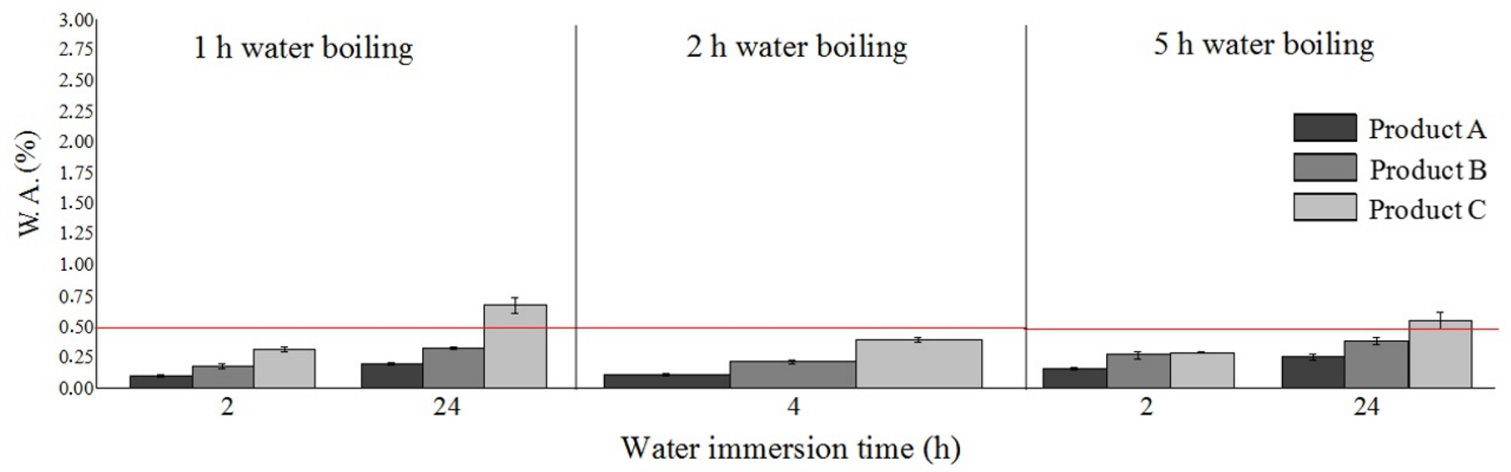

Figure 2. WA in function of the water immersion time obtained by the standard ISO 10545 for different water boiling times. 
Table 3. Analysis of variance (ANOVA) applied to the WA values in relation to the boiling time and water immersion time.

\begin{tabular}{|c|c|c|c|c|c|c|}
\hline \multirow{2}{*}{ Factor } & \multicolumn{2}{|c|}{ Product A } & \multicolumn{2}{|c|}{ Product B } & \multicolumn{2}{|c|}{ Product $\mathbf{C}$} \\
\hline & Test F & Test $\mathbf{P}$ & Test F & Test $\mathbf{P}$ & Test F & Test $\mathbf{P}$ \\
\hline Boiling time (h) & 4.34280 & 0.128518 & 278.4786 & 0.000468 & 1.457768 & 0.313795 \\
\hline Water immersion time $(\mathrm{h})$ & 30.65979 & 0.011610 & 985.5506 & 0.000071 & 9.418626 & 0.054606 \\
\hline Boiling time $\mathrm{x}$ water immersion time & 0.14968 & 0.724656 & 15.2335 & 0.029861 & 0.032252 & 0.868921 \\
\hline Error & \multicolumn{2}{|c|}{0.001034} & \multicolumn{2}{|c|}{0.000059} & \multicolumn{2}{|c|}{0.024850} \\
\hline Total standard deviation & \multicolumn{2}{|c|}{0.014989} & \multicolumn{2}{|c|}{0.030070} & \multicolumn{2}{|c|}{0.109820} \\
\hline $\mathrm{R}^{2}$ & \multicolumn{2}{|c|}{0.93104} & \multicolumn{2}{|c|}{0.99803} & \multicolumn{2}{|c|}{0.77372} \\
\hline
\end{tabular}

has no significant effect on WA, the values for the water immersion time are much greater than those for the boiling time and the interaction between the two. $\mathrm{R}^{2}$ represents the adequacy of the chosen model in relation to the experimental data. Table 3 shows that the model used is best applied to product $\mathrm{B}$.

In addition, we can clearly say that the conditions established by standard ISO 10545 are not sufficient to ensure the complete saturation of the pieces and, consequently, to determine the correct WA value for the analyzed products. In other words, a longer water immersion time than that specified is required to determine the correct value of WA in the evaluated products.

Figure 3 shows the WA value as a function of the water immersion time obtained by the vacuum method for different vacuum pressures. According to this figure, WA is increased from Product A to Product C, but the WA values of Product B and Product $C$ are out of specification $(>0.5 \%)$. The reduction of the pressure does not change this behavior. However, the WA values are increased further with decreased pressure. This means that the test conditions proposed by ISO are not enough to guarantee the determination of the correct WA value. The reduction of pressure should cause air extraction from the deeper regions of the plate. Consequently, water is more easily forced to penetrate the interior of the plate. Moreover, the water immersion time shows low significance on the WA. Even when increasing the water immersion time from 5 to $30 \mathrm{~min}$, for the vacuum pressures of both 6 $\mathrm{kPa}$ and $40 \mathrm{kPa}$, the WA does not vary significantly. This is clear in Table 4.
Table 4 shows that vacuum pressure shows greater significance (P-test) in the WA behavior than the water immersion time. For Product B, the value of the P-test is lower than 0.05 , but the effect of water immersion remains much smaller than that of the vacuum pressure. Table 4 also shows that the interaction between vacuum pressure and water immersion time does not show any significance on WA. In this way, one can say with $95 \%$ confidence that the vacuum pressure shows greater influence on the WA results of the evaluated products, in very good agreement with the behavior shown in Figure 3. The F-test in Table 4 is much greater for the vacuum pressure. The $\mathrm{R}^{2}$ values show that the model used was well fitted to the evaluated materials.

Figure 4 shows the values of WA as a function of the water immersion time, according to the standard ASTM C373. In this method, the water boiling time is $5 \mathrm{~h}$ and the water immersion time is $24 \mathrm{~h}$. Figure 4 shows that the materials evaluated by the standard ASTM C373 present the same general behavior as that shown in Figure 2 (ISO 10545). Table 5 shows that the water immersion time shows a greater effect on the WA behavior of the evaluated materials than the boiling time or the interaction between these two variables, although, for Product B, the boiling time is also significant $(\mathrm{P}<0.05)$. The $\mathrm{R}^{2}$ values are high, which indicates that the model adopted is adequate.

Regardless of the method used for the determination of WA, it is noted that the evaluated materials did not reach water saturation; i.e., they have not reached the maximum WA value, even at high values of water immersion time, in

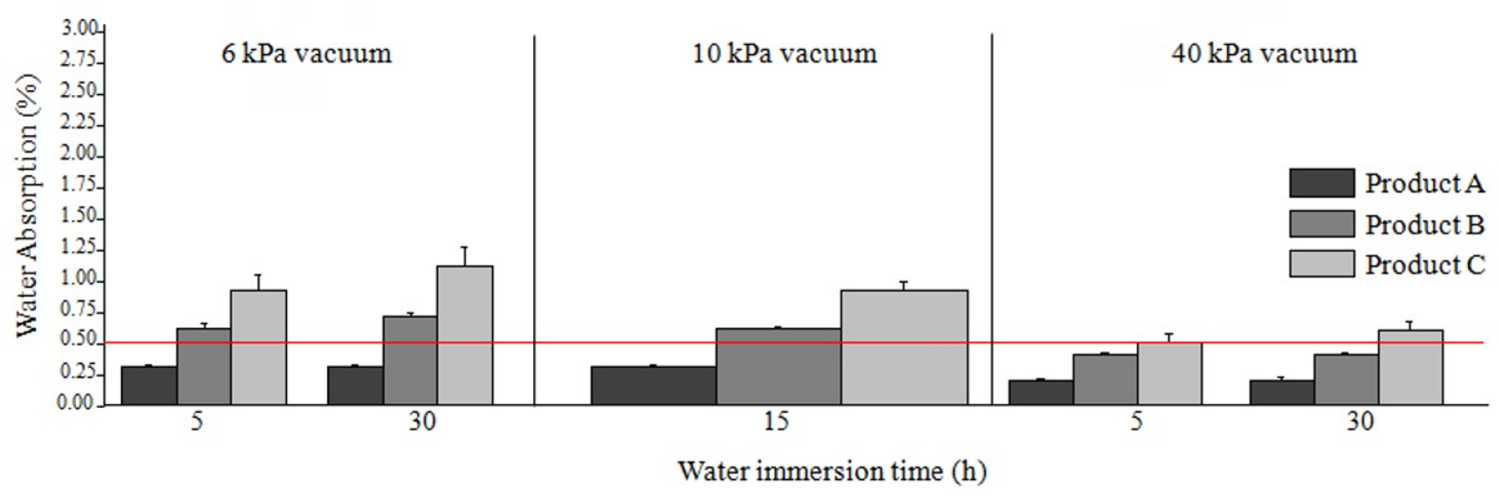

Figure 3. WA in function of the water immersion time obtained by the vacuum method for different vacuum pressures. 
Table 4. Analysis of variance (ANOVA) applied to the WA values in relation to the vacuum pressure and water immersion time.

\begin{tabular}{ccccccc}
\hline \multirow{2}{*}{ Factor } & \multicolumn{2}{c}{ Product A } & \multicolumn{2}{c}{ Product B } & \multicolumn{2}{c}{ Product C } \\
\cline { 2 - 7 } & Test F & Test P & Test F & Test P & Test F & Test P \\
\hline Vacuum pressure (kPa) & 82.78361 & 0.002805 & 382.8351 & 0.000292 & 20.55428 & 0.020083 \\
Water immersion time (h) & 8.20040 & 0.064385 & 34.1559 & 0.009984 & 2.06846 & 0.245950 \\
Vacuum pressure x water & 0.57386 & 0.503799 & 3.9223 & 0.141990 & 0.35960 & 0.590995 \\
immersion time & & & 0.000633 & 0.027810 \\
Error & 0.000454 & 0.086416 & 0.232844 \\
Total standard deviation & 0.013839 & 0.99268 & 0.88056 \\
$\mathrm{R}^{2}$ & 0.96719 & & & & \\
\hline
\end{tabular}

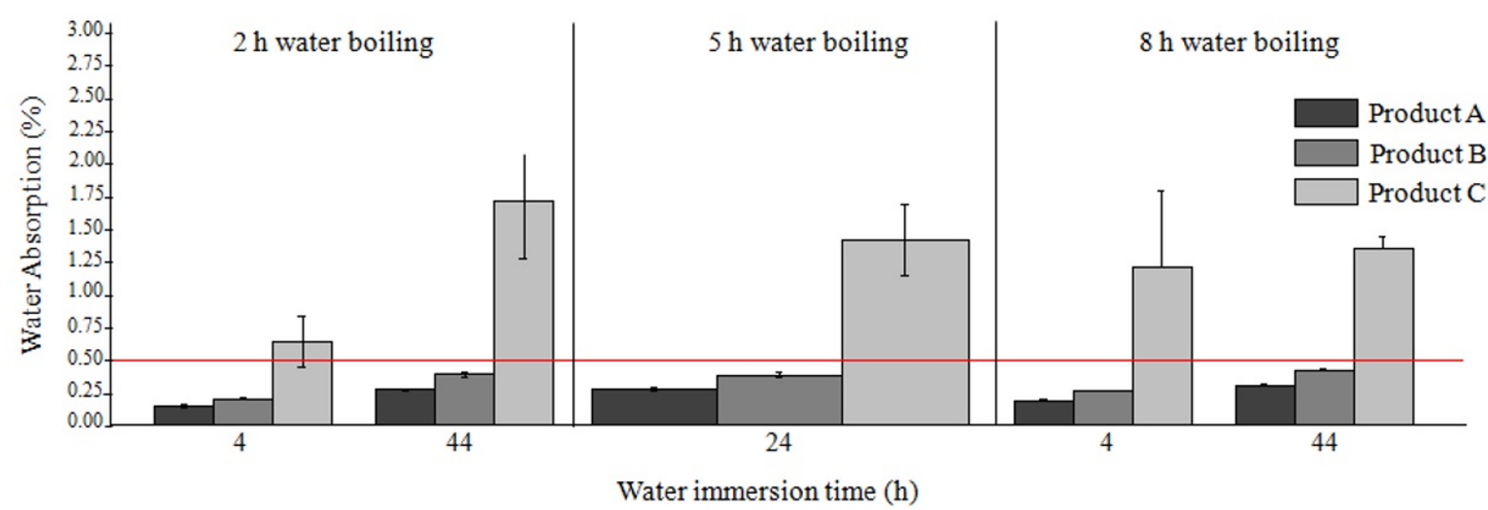

Figure 4. WA in function of the water immersion time obtained by the standard ASTM C373 for different water boiling times.

Table 5. Analysis of variance (ANOVA) applied to the WA values in relation to the boiling time and water immersion time.

\begin{tabular}{|c|c|c|c|c|c|c|}
\hline \multirow{2}{*}{ Factor } & \multicolumn{2}{|c|}{ Product A } & \multicolumn{2}{|c|}{ Product B } & \multicolumn{2}{|c|}{ Product C } \\
\hline & Test F & Test $\mathbf{P}$ & Test F & Test $\mathbf{P}$ & Test F & Test $\mathbf{P}$ \\
\hline Boiling time (h) & 0.27087 & 0.638717 & 31.0951 & 0.011384 & 0.15878 & 0.716948 \\
\hline Water immersion time $(\mathrm{h})$ & 13.56037 & 0.034698 & 390.8340 & 0.000283 & 22.14641 & 0.018158 \\
\hline $\begin{array}{c}\text { Boiling time } \mathrm{x} \text { water immersion } \\
\text { time }\end{array}$ & 0.03464 & 0.864232 & 69.2399 & 0.003638 & 13.62615 & 0.034484 \\
\hline Error & \multicolumn{2}{|c|}{0.003239} & \multicolumn{2}{|c|}{0.000607} & \multicolumn{2}{|c|}{0.052023} \\
\hline Total standard deviation & \multicolumn{2}{|c|}{0.018207} & \multicolumn{2}{|c|}{0.100002} & \multicolumn{2}{|c|}{0.675113} \\
\hline $\mathrm{R}^{2}$ & \multicolumn{2}{|c|}{0.82213} & \multicolumn{2}{|c|}{0.99393} & \multicolumn{2}{|c|}{0.92294} \\
\hline
\end{tabular}

the case of the boiling methods, and with reduced vacuum pressure value, for the method proposed by ISO.

Thus, several tests were performed to determine the minimum time at which the saturation of the pieces occurs in the three evaluated methods.

Figure 5 shows the evolution of WA as a function of the water immersion time. In the boiling method, as per standard ISO 10545 (Figure 5a), WA continued to increase at higher water immersion time than $5000 \mathrm{~h}$. We can conclude that this method is not effective to ensure the saturation of the evaluated ceramic plates when using the specified conditions.

In the boiling method ASTM C373, Product $\mathrm{C}$ reaches saturation after approximately $500 \mathrm{~h}$ of water immersion. However, the immersion time required for Products A and $\mathrm{B}$ to reach saturation is approximately $2500 \mathrm{~h}$. That is, although this method is more efficient than the previous one (ISO 10545), the water immersion time necessary to achieve saturation of the ceramic plates, and thus to correctly determine the WA value, exceeds $2500 \mathrm{~h}$ (over 100 days).

The vacuum method proposed by ISO, meanwhile, allows Products B and C to reach saturation in approximately $50 \mathrm{~h}$. Product A reaches saturation in $\sim 130 \mathrm{~h}$. Therefore, one can say that the vacuum method proposed by ISO is the most efficient of the three analyzed methods for the evaluated products, although the time required to yield information necessary for decision making in the industrial production process remains very high ( $>5$ days).

It is important to note that the WA values found by the vacuum method proposed by ISO are significantly higher than those found by other methods. This means that a much 
a

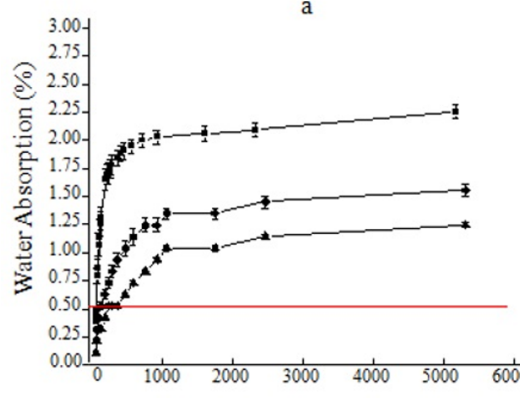

b

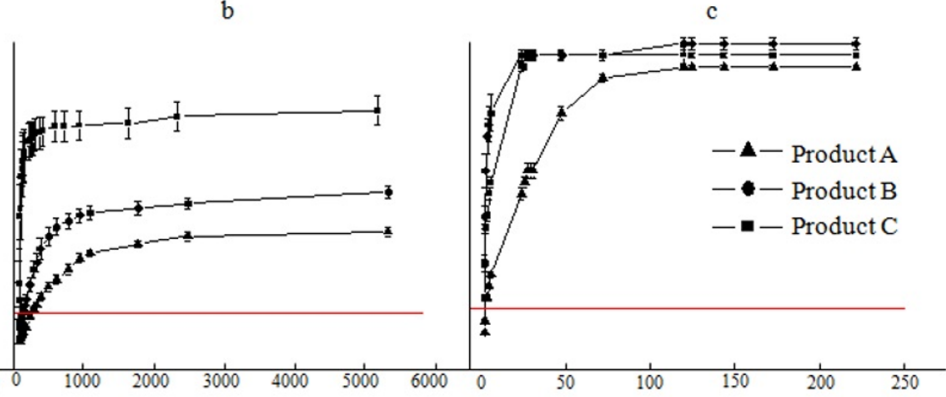

Water immersion time $(\mathrm{h})$

Figure 5. WA in function of the water immersion time obtained by the three evaluated methods: (a) ISO 10545, (b) ASTM C373 and (c) vacuum method proposed by ISO.

longer water immersion time is needed to achieve saturation. However, it should be considered that the test conditions of the boiling methods may be unsuitable for the saturation of pieces with such low porosities, and possibly also very low permeability values. In fact, for glazed porcelain stoneware ceramic tiles, the porosity may vary between $10-25 \%{ }^{13}$; however, the pores present very small sizes, entre 0.080 e $0.9 \mu \mathrm{m}^{14}$.

During boiling, the air in the pores and channels expands and is partially substituted by water, but some residual amount can remain after boiling. While cooling the piece within a fluid (water), the remained air in the pores contracts, creating negative pressure (vacuum) that it will be the driving force for the fluid to enter the piece. Thus, it is expected that the saturation time varies, among other factors, due to the viscosity of the fluid and the boiling time. However, when a vacuum system is created, more effective air withdrawal occurs in the pores and channels, substantially reducing the amount of air remaining inside the piece. When the vacuum period is interrupted and the piece is dipped into the fluid, the gaps are filled by water more quickly, because no residual air counteracts the entry of fluid into the piece.

A glazed porcelain stoneware ceramic tile can be considered a low permeability-medium to water under the conditions employed in the WA methods. The substitution of water to a less viscous fluid, as a gas, could improve the fluid penetration into de piece and hence measure WA in a more accuracy way. Thus, the helium gas pycnometry test was performed to determine the open porosity of the evaluated materials, as described in the Experimental Procedure.

Table 6 shows the results of WA estimated from the pycnometry test. In Table 6 we see the volume of the sample $\left(\mathrm{V}_{\text {apparent }}\right)$ and that obtained by the helium gas pycnometry
$\left(\mathrm{V}_{\text {real }}\right)$. If the piece had no open pores, the volumes obtained by pycnometry and by water immersion would be equal; the recorded difference in the values represents the volume of the open porosity $\left(\mathrm{V}_{\text {pores }}\right)$. This volume was converted into water mass, and the obtained value was divided by the mass of the dry sample $\left(\mathrm{m}_{\text {sample }}\right)$ to yield the indirectly measured value of WA. These values of WA can then be related to the water saturation for each one of the evaluated materials. In comparing such values with those ones obtained by the vacuum method (Table 7), we can say that they show a close match. However, the time required to determine WA by pycnometry is much shorter in relation to the current methods, at approximately $2-4 \mathrm{~h}$.

Table 7. Comparison among WA values (\%) obtained from the vacuum method at different vacuum pressures and the modified picnometry method.

\begin{tabular}{cccc}
\hline \multirow{2}{*}{ Product } & \multicolumn{2}{c}{$\begin{array}{c}\text { Vacuum method proposed } \\
\text { by ISO }\end{array}$} & $\begin{array}{c}\text { Modified } \\
\text { picnometry } \\
\text { method }\end{array}$ \\
\cline { 2 - 3 } & $\mathbf{6 ~ k P a}$ & $\mathbf{1 0 ~} \mathbf{~} \mathbf{~ P a}$ & \\
\hline $\mathrm{A}$ & $1.63 \pm 0.07$ & $1.56 \pm 0.05$ & $1.66 \pm 0.01$ \\
$\mathrm{~B}$ & $2.74 \pm 0.05$ & $2.64 \pm 0.03$ & $2.44 \pm 0.01$ \\
$\mathrm{C}$ & $2.84 \pm 0.08$ & $2.71 \pm 0.05$ & $3.01 \pm 0.01$ \\
\hline
\end{tabular}

Although the pycnometry test cannot be regarded as a standard method for determination of WA, there are strong indications that this technique could be used in the determination of such technological parameter for glazed porcelain stoneware ceramic tiles. Therefore, the modified pycnometry test requires systematic research to assess its potential for replacing current methods for the determination of WA.

Table 6. WA values obtained from the modified picnometry method.

\begin{tabular}{cccccc}
\hline Product & $\mathbf{V}_{\text {apparent }}\left(\mathbf{c m}^{3}\right)$ & $\mathbf{V}_{\text {real }}\left(\mathbf{c m}^{3}\right)$ & $\mathbf{V}_{\text {pores }}\left(\mathbf{c m}^{3}\right)$ & $\mathbf{m}_{\text {sample }}(\mathbf{g})$ & $\mathbf{W A}(\mathbf{\%})$ \\
\hline $\mathrm{A}$ & 7.209 & 6.9371 & 0.2719 & 16.2944 & 1.664 \\
$\mathrm{~B}$ & 7.244 & 6.8435 & 0.4005 & 16.3736 & 2.439 \\
$\mathrm{C}$ & 7.603 & 7.0862 & 0.5168 & 17.1308 & 3.008 \\
\hline
\end{tabular}




\section{Conclusion}

A comparative study of methods used to determine the water absorption of glazed porcelain stoneware ceramic tiles was performed in this work. The effects of the boiling time and water immersion time, for the boiling methods prescribed by standards ISO 10545 and ASTM C373, and the vacuum pressure and water immersion time, for the vacuum method proposed by ISO, were evaluated. In the boiling methods, the water immersion time was the most significant variable in determining the water absorption value, while the vacuum pressure showed the most pronounced effect on water absorption in the vacuum method. However, these methods could not ensure that the evaluated materials achieved water saturation. The vacuum method proved to be more efficient in achieving complete saturation, but the pressure had to be reduced from 10 to $6 \mathrm{kPa}$ and the water immersion time increased from $15 \mathrm{~min}$ to $130 \mathrm{~h}$ to obtain a steady-state water absorption value. The water absorption values obtained under these conditions matched very well with the values obtained by the modified method of helium gas pycnometry, indicating that this latter method represents an interesting perspective for a simple, relatively inexpensive, fast, and highly precise technique for the determination of water absorption in glazed porcelain stoneware ceramic tiles.

\section{References}

1. Callister Jr. WD. Ciência e Engenharia de Materiais: Uma Introdução. $5^{\mathrm{a}}$ ed. Rio de Janeiro: LTC; 2002.

2. Menegazzo APM, Lemos FLN, Paschoal JOA, Gouvêa D, Carvalho JC, Nóbrega RSN. Grés Porcelanato - Parte 1: Uma Abordagem Mercadológica. Cerâmica Industrial. 2000;5(5):710 .

3. García-Tem J, Saburit A, Bernardo E, Colombo P. Development of lightweight porcelain stoneware tiles using foaming agents. Journal of the European Ceramic Society. 2012;32(4):745-752. DOI: 10.1016/j.jeurceramsoc.2011.10.028

4. Correia MC. Investigação de problemas de colagem de revestimentos cerâmicos e de pedra natural em fachadas. Dissertation. Aveiro: Curso de Minerais e Rochas Industriais, Universidade de Aveiro; 2003.
5. Eren E, Kurama S, Solodov I. Characterization of porosity and defect imaging in ceramic tile using ultrasonic inspections. Ceramics International. 2012;38(3):2145-2151. DOI: 10.1016/j. ceramint.2011.10.056

6. Associação Brasileira de Normas Técnicas (ABNT). NBR 15463 - Porcelanato: Especificações. Rio de Janeiro: ABNT; 2013.

7. Associação Brasileira de Normas Técnicas (ABNT). NBR 13818 - Placas cerâmicas para revestimentos: Especificações e métodos de ensaio - Anexo B: Determinação da absorção de água. Rio de Janeiro: ABNT; 1997.

8. International Organization for Standardization (ISO). ISO 13006 : Ceramic tiles - Definitions, classification, characteristics and marking. Geneva: ISO; 2012.

9. ASTM International. ASTM C 373-88 - Standard Test Method for Water Absorption, Bulk Density, Apparent Porosity, and Apparent Specific Gravity of Fired Whiteware Products. West Conshohocken: ASTM International; 2006.

10. Chen Y, Zhang Y, Chen T, Liu T, Huang J. Preparation and characterization of red porcelain tiles with hematite tailings. Construction and Building Materials. 2013;38:1083-1088. DOI: 10.1016/j.conbuildmat.2012.06.056

11. Carbajal L, Rubio-Marcos F, Bengochea MA, Fernandez JF. Properties related phase evolution in porcelain ceramics. Journal of the European Ceramic Society. 2007;27(13):4065-4069. DOI: 10.1016/j.jeurceramsoc.2007.02.096

12. International Organization for Standardization (ISO). ISO 10545 : Ceramic Tiles - Part 3: Determination of water absorption, apparent porosity, apparent relative density and bulk density. Geneva: ISO; 1995.

13. Zanelli C, Raimondo M, Guarini G, Dondi M. The vitreous phase of porcelain stoneware: Composition, evolution during sintering and physical properties. Journal of Non-Crystalline Solids. 2011;357(16-17):3251-3260. DOI: 10.1016/j. jnoncrysol.2011.05.020

14. Kamseu E, Bakop T, Djangang C, Melo UC, Hanuskova M, Leonelli C. Porcelain stoneware with pegmatite and nepheline syenite solid solutions: Pore size distribution and descriptive microstructure. Journal of the European Ceramic Society. 2013;33(1314):2775-2784. DOI: 10.1016/j.jeurceramsoc.2013.03.028 